\title{
Enterprise Risk Management in ODL: The Imperatives and Lessons from the Zimbabwe Open University
}

\author{
Prof. Daniel Ndudzo (PhD)
}

\begin{abstract}
There has been a greater realization of the significance of risk management in higher education worldwide and more specifically in Open and Distance Learning institutions. Advancement of this interest has resulted in acceptance of the enterprise risk management (ERM) concept in these organizations. The author, in this research paper explores ERM in ODL, outlining the key issues, imperatives and lessons from experience and research. The qualitative research methodology was employed in the study with a predominantly case study research design. Data were gathered through direct and participant observation, document analysis and interviews with management and staff at the Zimbabwe Open University. The study revealed that successful risk management in ODL is dependent on leadership, the right organizational culture and a management style that promotes open mindedness and employee participation. The major barriers include inadequate training and supervision, lack of skills, focus on key priorities over key risks, culture of appeasement, tolerance of poor standards and inadequate communication. The study recommends wide use of ICT, skills development and leadership for cultural change as fundamentals for steering effective risk management in ODL.
\end{abstract}

Keywords: Risk, Enterprise Risk Management, Higher education, Open and Distance Learning, Corporate Governance

\section{Introduction}

The need for risk management to be embedded in organizational systems is the trending issue in the field of corporate governance in the internationally, in the Zimbabwe business community and in the Higher Education sector in particular. Risk management is not an alien concept in the general mix of business management and the pursuit of organizational goals. It is a strategic necessity for a $21^{\text {st }}$ century organization to incorporate risk management in operations as a way of protecting shareholder interests and also as a way of ensuring the continued sustainability of the business as going concern.

Risk, as defined by the Webster Dictionary (9th ed. 1985) is "the possibility of loss or injury." In the business context, the concept of risk includes not only the probability of loss but also the consequences of that loss or risk event. Risk is also generally defined as the combination of the probability of an event occurring that will impact the achievement of an organization's mission and objectives and the impact of its consequences. Management in ODL institutions need to appreciate that events with a negative impact on the organization represent risks that can undermine value creation and erode the existing value in the organization. It is the responsibility of management and the board to preserve and create value on behalf of shareholders, therefore, the need to institute a rigorous risk management process. Four categories of risks that can affect the success of organizations including ODL institutions have been identified; these include Strategic, Operational, Compliance and Financial \& Reporting risks.

\begin{tabular}{|c|c|}
\hline Type of risk & Examples \\
\hline Strategic & $\begin{array}{l}\text { - Reduction in demand for University programmes (due to change in business strategy in } \\
\text { industry, economic restructuring, reduced real incomes, new programmes by competitors, } \\
\text { changing technology) } \\
\text { Loss of top administrators, professors and senior academics to local, regional and } \\
\text { international competitors } \\
\text { Loss of intellectual property } \\
\text { - Negative impact to University reputation }\end{array}$ \\
\hline Operational & $\begin{array}{ll}- & \text { Disruption to Regional Campus operations } \\
- & \text { Inefficient use of resources } \\
\text { - } & \text { Physical property damage } \\
\text { - } & \text { Disruption of connectivity and online services } \\
\end{array}$ \\
\hline Compliance & $\begin{array}{ll}\text { Violation of laws or regulations such as: } \\
\text { - } \\
\text { - } & \text { Limbabwe Council for Higher Education (ZIMCHE) regulations } \\
\text { - } & \text { Environmental laws } \\
\text { - } & \text { Employee health \& safety regulations } \\
\text { - } & \text { Anti-Corruption laws } \\
\text { - } & \text { Tax and statutory laws } \\
\end{array}$ \\
\hline Financial \& reporting & - $\quad$ Government funding \& cashflows \\
\hline
\end{tabular}




\begin{tabular}{|l|ll|}
\hline & $\bullet$ & Credit risk \\
& $\bullet$ & Currency exchange, funding \& cash flow, credit risk \\
& Financial statements and adherence to standards \\
\hline
\end{tabular}

The Enron, WorldCom, and other corporate scandals of the early 2000s sparked a call for more comprehensive risk management (Prentice, 2008) after huge losses were incurred by shareholders and other stakeholders. Carney (2006) noted that risk related regulations were included in the listing standards of the New York Stock Exchange as a way of protecting shareholders and enhancing corporate integrity. The most extensive of these regulations is section 404 of the Sarbanes-Oxley Act, which required management of institutions to explain and assess the organizations' internal control structure and procedures for financial reporting.

\section{Enterprise Risk Management (ERM) in ODL}

Enterprise Risk Management is a institutional holistic framework to risk management applied by ODL directors, management and downstream employees to identify potential events that may affect the ODL institution, manage the associated risks and opportunities and provide reasonable assurance that the ODL institution's strategic objectives are going to be achieved.

\section{The ERM framework has the following benefits to ODL institutions;}

- It ensures the identification and resolving of risks related to compliance with regulations, laws and standards which has been a long standing perceived weakness of the ODL sector. ODL has experienced criticism regarding the quality of its outputs stemming from a perceived weak quality system and inadequate adherence to regulatory standards.

- $\quad$ ERM ensures effective and efficient use of resources during a period where there is a general reduction in support for higher education by governments worldwide. ERM enables an optimized business system through identification and elimination of bottlenecks and simplification of strategies.

- ERM is a vital cog in the implementation and promotion of good corporate governance standards. It promotes reporting and monitoring of compliance functions hence enables ODL institutions to attract support through goodwill. Governments and institutions sponsoring ODL institutions need to have a sense of assurance and security of the sustainability of their investments. ERM is a demonstration by ODL management to governments and other sponsors that their investments are in capable and diligent hands.

- ERM enhances coercion in ODL institutions, it analyses possible areas where inefficiencies and lack of coordination may emerge between ODL institutions' national centres and regional campuses may occur.

- There is enhanced decision making, planning and prioritization through a structured understanding of opportunities and threats throughout the hierarchical structures of the ODL institutions through the ERM system and processes.

- ERM supports and promotes value creation, growth, innovation and a world-class focus in ODL organizations through promoting a culture of research, mental alertness and employee involvement. It enables ODL institutions to be able to forecast, plan and deal with possible future problems and also to take advantage of opportunities as they arise.

Purpose of the study

The study is aimed at exploring the discipline of enterprise risk management and contextualizes it to the higher education ODL sector. The study draws lessons of the imperatives and key issues of ERM from the experiences of Zimbabwe's only ODL University, the Zimbabwe Open University.

\section{Statement of the problem}

Risk management is an integral function of management in the overall pursuit of good corporate governance. It has been adopted and adapted well in most sectors of business; however, the concept of enterprise risk management is still in its infancy in ODL hence the need for further development of ERM literature and perspective in ODL. Failure of effective ERM in ODL may result in diminished perceived value of ODL institutions, systems and their products.

\section{Objectives of the study}

- To evaluate the imperatives to ERM in ODL institutions

- To evaluate the barriers to effectiveness of ERM in ODL institutions

- To draw major ERM lessons from the experiences of the Zimbabwe Open University

Research questions

- What are the imperatives to successful ERM in ODL institutions?

- What are the barriers to effectiveness of ERM in ODL institutions?

- What are the major ERM lessons from the experiences of the Zimbabwe Open University?

Significance of the study

The study is set to enhance the development of good corporate governance practice in open and distance learning institutions through a relevant and ODL specific ERM model and literature. This is set to improve the standing of the ODL sector in the eyes of governments and other institutions critical to the funding and development of ODL. 


\section{Methodology}

The study employed the qualitative research methodology. A survey strategy and design was used to identify respondents to the study and the respondents were selected through the simple random sampling technique. The sample was made up of administrators, senior managers, council members and former council members of the ODL University. Data were generated through a combination of in-depth interviews, direct and participant observation and document analysis.

\section{Findings}

Risk management, like any other academic and administrative disciplines requires the perfect execution of imperatives and key success factors. The study canvassed several imperatives for successful risk management in ODL as follows;

\subsection{Imperatives for effective risk management in ODL}

- A comprehensive risk assessment process by Management: - this process should be kick-started and led by Senior Management but cascaded down and horizontally throughout the organizational hierarchy. It is important that Regional campuses are given priority and due attention throughout the process as they are the most important service centres for students and other key stakeholders.

- Conclusions to the assessment by Management should be related to strategic risk: - risk management feedback and submissions to senior management and the Vice Chancellor should be streamlined and reflect a thorough assessment and consideration of strategic risk. Decisions made by Senior Management are strategic in nature and they should address strategic risk factors. Resources should be allocated to key strategic risks and strategies to protect the institution and help achieve goals

- Problems and solutions should be presented and discussed within a comprehensive context of competing priorities and resources: - ODL institutions by their nature are complex in terms of allocation of resources and prioritization of needs especially for Regional Campuses. A clear understanding of an ODL institution's Campuses and departmental needs is required when considerations are made for resource allocation.

- Solutions should be transparently vetted in terms of alternative approaches: - respondents indicated that optimal solutions are only derived when open minds are applied and several options are weighed in the form of cost benefit analysis. Solutions should also be discussed in terms of risk/ return characteristics of options.

- Solutions should address capital, student, academic, admissions and diversity risks which characterize ODL institutions in a localized and specific model. The ODL system does requires that campuses and key risk areas be analysed in their unique geographical areas and disciplines.

\subsection{Risk management at the Zimbabwe Open University}

Risk management is viewed as an imperative to the sustainability of the ODL institution and its survival. The Zimbabwe Open University management and board members decided to have risk management as part of its formal institutional functions. The study revealed that the University had institutionalized risk management at board/ Council level and within the departments of the institution.

\subsection{The rationale behind risk management in ODL}

Several reasons were advanced as to what necessitates risk management in open and distance learning institutions by the residents. The major reasons for risk management in ODL identified were;

- A requirement for good corporate governance - Respondents indicated that ZOU was a government owned institution and had an obligation to uphold the highest standards of corporate governance. Risk management was viewed by respondents as a way of assuring the government and the main shareholder and funder of the university that the university was run professionally as a going concern and management was committed to protect the government's investment.

- The need to guard against damaging reports - the respondents indicated that the university had in the past suffered losses due to bad publicity, hence; there was need for strategies to forecast and counter such risks.

- Ensuring the safety of assets - The study revealed that the ODL institution views risk management as an imperative in ensuring the safety of fixed assets and other non fixed assets such as debtors, cash and goodwill.

- Need for assurance - the ODL market is a sensitive market which needs high levels of reassurance for students, regulators and employers. A study by Ndudzo (2014) revealed that assurance was the most important service quality dimension for ODL students. Risk management is viewed in ODL circles as a tool for assurance.

\subsection{Responsibilities}

\subsubsection{University Council}

The University decided to house the risk management function under the former Audit Committee of Council thereby creating an Audit and Risk management Committee of Council. The Committee was responsible for oversight and supervision of the university's risk management strategy.

\begin{tabular}{llr}
\hline DOI: $10.9790 / 487 X-1901032428$ & www.iosrjournals.org & $26 \mid$ Page
\end{tabular}


The University Council is responsible for ensuring that there is an integrated risk management approach to problems, solutions, and decisions, in the context of strategic goals and objectives of the University. The Council provides a strategic and comprehensive oversight of risk management processes at ZOU by integrating risk considerations and risk assessment and planning into the Audit and Risk management Committee of Council work.

\subsubsection{Management}

The University's management, superintended by the Vice Chancellor leads a risk assessment process identifying the risks faced by the University. The team embarks on an institution wide risk identification and prioritization. Management is also responsible for development of operational risk management plans and mitigating activities and responses to prepare the university to exploit opportunities as and when they arise and to minimize impact of events. Finally management empowers and enables risk management through allocation of resources, training of employees and leading the process.

\subsubsection{Internal Audit}

Risk management has been the primary responsibility of audit departments in most organisations and the Zimbabwe Open University is no exception. The Audit Department led by the Senior Internal Audit is responsible for unbiased risk assessment and reports to the Vice Chancellor. The University, however, embarks on a comprehensive risk assessment process which starts from Departments and Regional Campuses feeding into the main report to the Vice Chancellor.

\subsubsection{Risk management Policy and procedure manual}

The researcher noted that risk management could only become operational in institutions if it had enabling policies, regulations and clearly outlined procedures for employees. The study revealed that the Zimbabwe Open University had developed an enabling policy and a procedure manual for risk management.

\subsubsection{Organizational culture}

The study revealed that risk management in open and distance learning is hugely dependent on organizational culture. The success of risk management in its introductory phases at the Zimbabwe Open University was hugely attributed to a culture of employee involvement, innovation and participation. Respondents indicated that employees at the University were instrumental in identifying some of the most important risks that management could not easily detect.

\subsection{Barriers to effective risk management in ODL \\ 4.5.1 Organisational Culture of appeasement}

The study revealed that too often, organizations fail to implement effective risk management systems because of the inclination and tendency of subordinates and work colleagues to report positive information rather than highlighting possible negative scenarios and outcomes. This results in a suppressed risk management atmosphere where risks are neither reported nor assessed independently nor objectively.

\subsubsection{Tolerance of poor standards and risk}

The respondents indicated that tolerance of poor performance standards, lack of effective punitive or corrective action after low performance outputs and outcomes and tolerance of risk and risky behavior was an important barrier to risk management in most organizations. The study revealed that there was strategy to tackle this particular problem at ZOU through the implementation of quality standards and performance management mechanisms.

\subsubsection{Communication breakdown}

The researcher noted that inadequate communication between departments, faculties, committees and teams was a major impediment to effective risk management. Lack of effective communication result in some risks being ignored and not paid proper attention. Risk management requires a holistic and integrated management approach with cooperation and coordination from all facets of the organization hence the importance of communication.

\subsubsection{Focus on key priorities to the detriment of key risks}

The study revealed that risk management is often impacted in the ODL institution by a focus on factors or activities perceived as more important than risk management. These include attending to regulatory requirements, government, market and student concerns. The perceived significance of the issues results in the establishment of an organizational culture and influence on the behavior of administrators and other employees to the detriment of risk management.

\subsubsection{Inadequate training and supervision}

The study revealed that risk management was being impacted significantly by the lack of training. The risk management philosophy in the institution requires participation by all employees but there is a limited number of trained as educated professionals in the discipline, this also applies to leadership and the effectiveness of supervision in risk management. 


\section{Conclusions}

The study concludes that risk management in ODL is a management function which requires commitment and dedication at all levels. It should be managed in a truly holistic manner with coordination and effective communication because of the geographical dispersion of ODL institutions. Effective leadership is the trump-card to effective enterprise risk management in ODL hence the importance of organizational leaders.

\section{Recommendations}

The study recommends the following measures for the effectiveness of enterprise risk management in ODL;

\section{- Skills development}

Enterprise risk management like other disciplines require skilled and competent staff hence ODL institutions should invest in ERM training and development.

\section{- Leadership and cultural change}

ERM is hugely dependant on effective leadership and an enabling organisational culture; ODL institutions should promote an organizational culture that allows positive criticism and departure from the norm. This would allow employees to identify and notify management of potential risks.

\section{- Wide use of ICT}

The effectiveness of risk management in geographically dispersed ODL institutions could be enhanced by the use of risk management enabling ICT resources. ICT can merge information from different sources and enable management to efficiently develop policies and strategies for the whole organization in an efficient and effective way.

\section{References}

[1]. Scott Keller and Colin Price, Beyond Performance: How Great Organizations Build Ultimate Competitive Advantage, John Wiley \& Sons, 2011

[2]. Merriam Webster's Dictionary 1018 (9th ed. 1985)

[3]. Robert Prentice, Enron: A Brief Behavioral Autopsy, 40 A.M. BUS. L.J. 417 (2008)

[4]. U.S.C. 7262 (2006); William J. Carney, The Costs of Being Public After Sarbanes-Oxley: The Irony of "Going Private,"

[5]. NYSE, INC., Listed Company Manual; Robert B. Thompson, Collaborative Corporate Governance: Listing Standards, State Law and Federal Regulation, 38 Wake Forest L. Rev. 961 (2003) (explaining and analyzing changes to listing standards). 